\title{
Desempenho na Gestão Pública do Programa Bolsa Família sob a Perspectiva de Análise do Índice de Gestão Descentralizada (IGD)
}

\section{Performance in the Public Management of Brazil's Bolsa Familia Program in the Light of the Decentralized Management Index (DMI)}

\author{
Ambrozina de Abreu Pereira Silva ${ }^{1}$ \\ Marco Aurélio Marques Ferreira² \\ Doraliza A. Abranches Monteiro³
}

\section{Resumo}

0 presente estudo teve como objetivo verificar o desempenho da gestão pública do Programa Bolsa Família (PBF), bem como identificar fatores associados à eficiência e à qualidade da gestão do PBF, tomando como referência o Estado de Minas Gerais. 0 trabalho toma como referência o Índice de Gestão Descentralizada (IGD), que pode ser considerado, simultaneamente, uma ferramenta de monitoramento do desempenho dos municípios, e um instrumento de incentivo financeiro à boa gestão local do programa. As abordagens teóricas utilizadas basearam-se na execução e descentralização de políticas públicas. Para a operacionalização do estudo foram utilizadas estatísticas descritivas como base para a criação dos escores de desempenho municipal na gestão do PBF, e a técnica de Correlação de Momentos de Pearson para identificação dos fatores associados à eficiência e

\footnotetext{
1 Mestre em Administração pela Universidade Federal de Viçosa. Professora assistente da Universidade Federal de Outro Preto (UFOP). Pesquisadora do Grupo Administração Pública e Gestão Social - APGS/ UFV. ambrozinaap@yahoo.com.br

2 Doutor em Economia Aplicada pela Universidade Federal de Viçosa. Professor-adjunto da Universidade Federal de Viçosa (UFV). Coordenador do Grupo Administração Pública e Gestão Social - APGS/UFV. marcoaurelio@ufv.br

3 Doutoranda em Administração da Universidade Federal da Bahia (Ufba). Mestre em Administração pela Universidade Federal de Viçosa. Pesquisadora do Grupo Administração Pública e Gestão Social - APGS/UFV. doraliza_monteiro@yahoo.com.br
} 
qualidade da gestão do PBF. Grande parte dos municípios possui bom desempenho na gestão do Programa, porém destacou-se a existência de municípios com "Péssimo" desempenho no IGD, uma vez que não conseguiram atingir o índice mínimo para recebimento dos recursos, mostrando que estes municípios apresentam falhas na gestão do PBF. Além dos fatores empregados na formação do IGD, o tamanho dos municípios e a quantidade de beneficiários parecem influenciar a qualidade e eficiência da gestão do PBF. Fica evidente a necessidade de aprimoramento dos mecanismos de monitoramento de informações e de acompanhamento das condicionalidades, visando a garantir à população beneficiada 0 acesso a direitos básicos como educação e saúde, atingindo, assim, 0 objetivo do PBF, que é reduzir a pobreza entre gerações e apoiar as famílias no cumprimento de seus direitos fundamentais.

Palavras-chave: Administração pública. Gestão pública. Programa Bolsa Família.

\begin{abstract}
This study aimed at verifying performance in the public management of Brazil's Bolsa Família Program (BFP) - a conditional cash transfer program - and also at identifying factors associated with efficiency and quality in the program's management in the state of Minas Gerais, Brazil. As a reference for this study, the Decentralized Management Index (DMI) acts as a financial incentive for a suitable local management of the program. A theoretical framework was developed based on the enactment and decentralization of public policies. Descriptive statistics were used as a basis to measure the local management of the BFP and the Pearson product-moment correlation procedure was used to identify factors associated with efficiency and quality in the program's management. The results show that some towns have very low performance on the DMI since they were not able to reach the minimum level for the provision of resources, which illustrates flaws in the program's management. Besides the factors adopted for developing the DMI, town size and the number of beneficiaries seem to influence the BFP quality and efficiency. Moreover, information monitoring and conditionality accompaniment mechanisms need clear improvement to ensure the population access to basic rights, such as education and healthcare, thus fulfilling with the objectives of the PBF: to reduce poverty among generations and to provide families with support to meet the fundamental rights they are entitled.
\end{abstract}

Keywords: Public administration. Public management. Brazil's Bolsa Família program. 
Em 2006, com o intuito de mensurar os resultados de gestão e apoiar os municípios nas atividades do Programa Bolsa Família, o governo federal regulamentou o apoio financeiro aos municípios para o auxílio ao cumprimento desse objetivo. $\mathrm{O}$ apoio financeiro transferido mensalmente é baseado no desempenho de cada município na gestão do Programa Bolsa Família. Dessa forma, os municípios que alcançarem os melhores resultados na gestão do Programa receberão mais recursos.

Visando a mensurar o desempenho das administrações municipais no cumprimento das metas institucionais regulamentadoras do programa, foi criado o Índice de Gestão Descentralizada do Programa Bolsa Família (IGD). O IGD é um índice de eficiência da gestão que combina a integridade, a qualidade e a atualização das informações constantes no Cadastro Único e informações sobre os cumprimentos das condicionalidades da área de educação e de saúde (Bolsa Família Informa, 2008a).

Uma das questões amplamente discutidas no contexto econômico e social brasileiro, é relativa à alocação dos recursos em programas sociais (Chiechelski, 2005). Daí a relevância de se estudar a temática, principalmente em um momento em que se discute, no cenário nacional, a equidade, a transparência e a eficiência na alocação dos recursos públicos.

O presente estudo, portanto, teve como objetivo verificar o desempenho da gestão pública do Programa Bolsa Família, bem como identificar fatores associados à eficiência e qualidade da gestão do PBF em Minas Gerais.

Sua importância é respaldada, pois sabe-se que o estudo e a avaliação da gestão de políticas públicas existentes podem proporcionar informações e interpretações mais adequadas para instrumentalizar o processo de planejamento, permitindo escolher as melhores opções dentre os programas e projetos a serem introduzidos, ou propiciar a avaliação da qualidade da efetivação ou efeitos produzidos pelos programas e projetos adotados. 
A gestão do Programa Bolsa Família é realizada pelo secretário da área onde está localizado o Programa (assistência social, educação, saúde, planejamento, dentre outros). Desse modo, o gestor municipal do Programa Bolsa Família assume a interação política entre a prefeitura, o governo estadual e o Ministério do Desenvolvimento Social e Combate à Fome (MDS) para a execução do Programa e do Cadastro Único.

Por isso, o gestor deve ter poder de decisão, de mobilização de outras instituições e de articulação e coordenação entre as áreas de assistência social, educação e saúde, pois estas estão envolvidas na operação do Programa Bolsa Família e garantem o acompanhamento dos beneficiários e a verificação das condicionalidades exigidas para a participação no programa (Bolsa Família Informa, 2008b).

Neste sentido, o IGD pode ser considerado, simultaneamente, uma ferramenta de monitoramento do desempenho dos municípios, e um instrumento de incentivo financeiro à boa gestão local do programa, uma vez que permite remuneração por resultados, algo complexo na administração pública, em especial considerando as relações inter e intragovernamentais. O IGD permite, ainda, monitorar a evolução da gestão municipal, facilitando a identificação de problemas e a intervenção corretiva em áreas estratégicas para os resultados do PBF (Cunha; Pinto, 2011).

\section{Referencial Teórico}

\section{Execução de Políticas Públicas}

São diversas as definições de políticas públicas e, embora o campo da política pública seja amplo, abrangendo diversos atores sociais como indivíduos, instituições, interações, ideologias e grupos de interesses, neste estudo ela será tratada como um conjunto de programas ou objetivos que tem o governo em determinada área, com consequências de fatos e decisões que implicam certa evolução ou modificação da realidade (Castanhar, 2006). 
Na concepção de Coutinho (2000), a administração pública voltada para o cidadão pode ser definida como um modelo gerencial cujo objetivo é oferecer serviços públicos de qualidade, atendendo melhor às demandas dos seus usuários. Esse seria um modelo ideal para levar melhorias a uma sociedade tão desigual, que vive em situação de vulnerabilidade.

Analisar o papel que vem sendo desempenhado pelos governos locais, no que se refere ao estímulo ou constrangimento à instituição de mecanismos pluralistas e republicanos de gestão das cidades, assim como buscar padrões de gestão local e de execução de políticas públicas e de provisão de serviços, não é tarefa fácil devido à diversidade existente entre os municípios brasileiros (Souza, 2004).

Segundo Matias-Pereira (2008), a existência de grande diversidade cultural, diferentes regimes políticos e formações históricas específicas de cada unidade territorial, imprime em cada um deles uma feição única, o que leva a entender as diferenças entre formas de administrar, objetivos, função e papel da administração pública no mundo. A capacidade da administração pública de realizar e obter resultados que beneficiem a sociedade, em geral, depende da forma como se encontra estruturada. Sendo assim, a organização é o ponto de partida para o sucesso da administração pública.

Dentre os esforços atuais de mudança da realidade socioeconômica do país, têm se destacado os programas de transferência de renda. Essa política foi introduzida no Brasil a partir dos anos 1990, e abrange vários aspectos da Administração Pública, como os econômicos, sociais, assistenciais e educacionais. Por mencionar aspectos da concentração de renda e pobreza, sendo este um grande desafio para as políticas públicas e o desenvolvimento do país, o seu estudo e análise permite desenvolver elementos que ajudam a compreender e avaliar a disseminação de outras políticas.

Dessa forma, Silva e Melo (2000) propõem que o monitoramento e a avaliação das políticas públicas sejam considerados instrumentos que permitam a constante reformulação, sujeitos à corroboração ou ao abandono das 
políticas, principalmente pelo fato de que as políticas públicas são instituídas fundamentalmente por meio de redes de agentes públicos e de um campo interorganizacional, formado pelas esferas municipal, estadual e federal.

Nessa perspectiva, surge a necessidade de conhecer o resultado da gestão de programas de transferência de renda, como o Programa Bolsa Família, principalmente no Brasil, em que as desigualdades visualizadas nas áreas educacionais, da saúde, além das diferenças existentes nas condições financeiras, políticas e administrativas de Estados e municípios, demandam por um Estado ativo, promotor da justiça social. A escassez clama por esforços de otimização, o quadro global competitivo requer um Estado regulador e uma gestão econômica consistente que tem o cidadão como o foco da ação pública (MPOG, 2003).

Dessa forma, o desempenho da organização pública é aceitável ou satisfatório quando, por meio da utilização correta dos recursos, os objetivos estabelecidos no desenho da política pública são atingidos e as necessidades dos cidadãos são supridas. Isso porque cabe ao governo o provimento de políticas públicas (Souza, 2006), embora também verifique empresas assumindo esses papéis, por meio dos programas de responsabilidade social corporativa.

Esses fatores requerem redefinição de estratégias e capacidade de o poder público formular e instituir políticas públicas de forma eficiente, transparente, participativa e de qualidade, parâmetros fundamentais para a avaliação de políticas públicas.

A avaliação que pretende se realizar neste estudo é assentada no processo, conforme proposto por Castioni (1999), Monteiro (2002) e Santos e Santos (2007), e especificamente no processo de gestão, e não propriamente nos impactos dessa política para a sociedade, embora possa se fazer reflexões acerca deste. $\mathrm{O}$ foco reside, portanto, na eficiência com que o programa é conduzido em vista dos resultados esperados. $\mathrm{O}$ aprimoramento, o monitoramento e a avaliação de programas, contemplando a avaliação dos 
processos e da eficiência das ações, apontam caminhos e soluções, além de serem realizados com o intuito de fundamentar as tomadas de decisão (Monteiro, 2002).

Assim, a avaliação de políticas e programas tornou-se tanto compromisso quanto desafio e a demanda por avaliação têm impelido os governos nos âmbitos nacional e subnacional a constituir rotinas e estruturas especializadas (Santos; Santos, 2007), de tal modo que acompanhar a criação de programas sociais como o Programa Bolsa Família num país como o Brasil é um grande compromisso e desafio, principalmente porque os militantes dessa área possuem o entendimento de que esses programas demandam uma estrutura burocrática mínima, que associa transparência de gastos públicos aos resultados socioeconômicos de sua efetivação.

A avaliação dos processos e da eficiência das ações, portanto, são medidas para se avaliar a gestão do Programa Bolsa Família, posto que quase sempre os recursos são limitados ou escassos e, de acordo com Souza (2006), analisar políticas públicas significa, muitas vezes, estudar o "governo em ação". Assim, a avaliação da gestão do programa Bolsa Família é realizada pelo acompanhamento do Cadastro Único e das Condicionalidades, uma vez que estas estão diretamente atreladas à eficiência e à qualidade do programa e possuem parâmetros para avaliar a gestão do Programa Bolsa Família.

\section{Descentralização de Políticas Públicas}

A busca de alternativas para a modernização da gestão pública tem sido altamente influenciada pelas ideias de participação e descentralização devido à necessidade de repassar deveres e obrigações dos níveis superiores de governo para os níveis inferiores (Souza, 2007). Dessa forma, com a proposta da descentralização político-administrativa coube a coordenação e as normas gerais à esfera federal, e a participação da população na formulação de políticas e controle das ações em todos os níveis (Arns, 2005). 
O processo de descentralização tem sido conhecido como uma das formas para melhorar a eficiência alocativa do setor público, pois aproxima a gestão pública dos cidadãos, concorrendo para o incremento da democracia, da cidadania, da responsabilidade social, do atendimento às necessidades da população, bem como contribui para introduzir concorrência na provisão de serviços públicos locais, com significativo impacto sobre a gestão pública (Souza, 2007).

A provisão ou gestão dos serviços ou da política pública deixou de ser atribuição exclusiva do Estado. Inovações políticas desenvolvidas no âmbito local vêm alcançando a promoção de ações integradas, o estabelecimento de vínculos de parcerias com outros níveis de governo e com governos de outros municípios, a criação de novas formas de articulação entre Estado, sociedade civil e mercado, incluindo novos atores na formulação e execução das políticas públicas e o compartilhamento da responsabilidade pela provisão ou gestão dos serviços ou da política pública (Farah, 2001).

Assim, o que se observa é uma redistribuição das responsabilidades referentes às ações e serviços entre os vários níveis de governo (Federal, Estadual e Municipal), resultado de uma redefinição das atribuições e com reforço do poder municipal (municipalização), aumentando, assim, as tarefas dos municípios em várias áreas como a saúde e a educação. A municipalização permitiu a cada município conhecer seus problemas e agir de acordo com as suas necessidades, responsabilizando-se pela gestão dos serviços básicos.

Numa posição mais crítica, alguns autores, como Abrucio e Soares (2001) e Arretche (1996), destacam que repassar o poder às municipalidades pode gerar novas formas de clientelismo e transferir encargos sem que os municípios estejam preparados para produzir as políticas públicas. Segundo Ortiz (2007), são diversas as razões para a descentralização: a dimensão continental do país, as diferenças regionais e uma enorme quantidade de municípios existentes (mais de 5.500), dos quais a maioria é de pequeno porte. Giambiagi e Além (2000), reforçando essa vertente, demonstram 
que a descentralização é justificada por diferentes razões, sendo fatores econômicos, culturais, políticos e institucionais e geográficos. Assim, a descentralização depende de características específicas de cada país e regiões.

Nesse sentido, no tocante aos programas sociais do governo federal, a instituição descentralizada dos programas do Ministério do Desenvolvimento Social e Combate à Fome (MDS) pressupõe sua articulação ou mesmo integração, no âmbito da família, da comunidade e do território. Isso significa que a gestão e a operacionalização dos programas dependem da coordenação não só entre setores dentro de um nível de governo, mas entre seus vários níveis governamentais - União, Estados e municípios (Sousa, 2006).

Desde a criação do Programa Bolsa Família, em 2003, até 2005, sua gestão era realizada pela Secretaria Nacional de Renda e Cidadania (Senarc). A partir de 2005, o MDS promoveu a descentralização da Gestão de Benefícios do Programa Bolsa Família, permitindo aos gestores municipais do programa administrar, em seu próprio município, a transferência de renda às famílias beneficiadas pelo programa.

Dessa forma, a gestão do Programa Bolsa Família é descentralizada e compartilhada por União, Estados, Distrito Federal e municípios. Os três entes federados trabalham em conjunto para aperfeiçoar, ampliar e fiscalizar a execução do Programa, instituído pela Lei 10.836/04 e regulamentado pelo Decreto $n^{0}$ 5.209/04 (MDS, 2011a). Com essa ação os municípios ganharam maiores responsabilidades, assim como passaram a lograr recursos humanos e técnicos qualificados para o novo esboço de atividades na gestão do programa.

Assim, o gestor municipal do Programa Bolsa Família tem como principais funções: assumir a interlocução política entre a prefeitura, o MDS e o Estado para a efetivação do Bolsa Família e do Cadastro Único; coordenar a relação entre as Secretarias de Assistência Social, Educação e Saúde para o acompanhamento dos beneficiários do Programa Bolsa Família e a verificação das condicionalidades; coordenar a execução dos recursos transferidos pelo 
governo federal para o Programa Bolsa Família nos municípios; coordenar a interlocução com outras secretarias e órgãos vinculados ao próprio governo municipal, estadual e federal e, ainda, com entidades não governamentais (Bolsa Família Informa, 2008b).

Com a transferência da administração para os gestores municipais, ocorreu o processo de descentralização das decisões e da delegação das funções, criando, portanto, o IGD, para apoiar e estimular os municípios a investir na melhoria da gestão do Programa Bolsa Família (PBF), avaliando a gestão municipal e oferecendo apoio financeiro aos municípios com bom desempenho.

Para Mosher (apud Campos, 1990, p. 33), "quem falha no cumprimento de diretrizes legítimas é considerado irresponsável e está sujeito a penalidades”. Segundo Trosa (2001, p. 264), uma visão moderna de responsabilidade torna-se necessária, uma vez que esta não pode ter como base a ameaça e a sanção, mas deve transmitir um sentimento interiorizado que “cada um faz parte da solução e não apenas do problema”. Na visão de Przeworski (1998), se os cidadãos têm como saber se os governos estão ou não atuando na defesa dos interesses públicos e podem lhes aplicar as sanções apropriadas, pode-se dizer que estes governos são accountable.

No Programa Bolsa Família a palavra accountability é de grande destaque, pois muitos autores, além de discutirem a real eficácia do programa, revelam que a participação de atores políticos tão diversos com vistas a atingir um objetivo comum não é simples de ser obtida, por esse motivo deve haver práticas de accountability, controle interno e externo para ajudar neste processo e auxiliar a evitar problemas que comprometam a qualidade da gestão municipal. E o accountability parece ser um dos propósitos, também, do IGD.

\section{Metodologia}

Esta seção está dividida em três partes, sendo a primeira área de estudo, fonte de dados e amostra, a segunda os métodos de pesquisa utilizados, e a terceira a composição do Índice de Gestão Descentralizada (IGD). 


\section{Área de Estudo, Fonte de Dados e Amostra}

O estudo será realizado por meio da análise de dados secundários obtidos com as informações e publicações do governo federal/Ministério de Desenvolvimento Social e Combate à Fome - Programa Bolsa Família/ IGD e Instituto Brasileiro de Geografia e Estatística (IBGE). A escolha de Minas Gerais se justifica por ser um Estado que se destaca pelas disparidades regionais. Embora possua o $3^{\circ} \mathrm{PIB}$ estadual entre as Unidades Federativas do país, parques industriais diversificados e IDH acima de 0,80 , em seus espaços geográficos existem contrastes. Coexistem, em um mesmo escopo territorial, regiões dinâmicas e modernas em contraste com regiões atrasadas e estagnadas, com população ainda vivendo na faixa da pobreza. Vale destacar também que Minas Gerais é o maior Estado da Região Sudeste, quarto do país em área, segundo em população e possui a terceira economia do país, ficando abaixo de São Paulo e Rio de Janeiro.

Destaca-se que Minas Gerais, juntamente com Bahia e Ceará, são os Estados que apresentam maior participação nas transferências do programa Bolsa Família, com valores em média correspondentes a 10,05\%, 13,51\% e 8,63\% respectivamente (Monteiro, 2008). Até julho de 2011 foram transferidos em média $R \$ 129,8$ milhões mensais para 1,1 milhão de famílias mineiras (MDS, 2011).

\section{Métodos de Pesquisa}

Para a sumarização dos dados foi realizada uma Análise Exploratória de Dados (AED), visando a compreender, descrever e resumir o comportamento do conjunto de dados com o objetivo de conhecer suas características importantes.

A AED compõe a análise de medidas de tendência central como média, mediana e moda; medidas de dispersão como o desvio-padrão, a amplitude e a assimetria, que visa a verificar como os dados estão distribuídos e concentrados; e verificar a presença de outliers. 
Para verificar a intensidade da relação no conjunto de valores quantitativos emparelhados, foi realizado o cálculo do coeficiente de correlação linear - Correlação de Pearson.

Os valores do coeficiente de correlação podem variar de 0 a 1 , em que 0 significa correlação neutra e 1 correlação plena. O sinal indica o sentido da correlação. Assim, negativo significa associação inversa, entre o par de variáveis, e positivo, associação na mesma direção.

As variáveis utilizadas pelo estudo foram: População, Recursos Transferidos no Mês para Apoio à Gestão $(\mathrm{R} \$)$, Teto de Recursos para Apoio à Gestão (R\$), Total de Famílias Beneficiadas pelos Programas, Índice de Validade dos Cadastros, Índice de Atualização de Cadastro, Índice de Condicionalidade de Educação, Índice de Condicionalidade de Saúde e Índice de Gestão Descentralizada do Mês (IGD).

As variáveis foram escolhidas com base na composição do IGD, bem como nas informações que o Ministério do Desenvolvimento Social e Combate à Fome (MDS), Bolsa Família Informa e o Instituto Brasileiro de Geografia e Estatística (IBGE), possuíam sobre o Programa Bolsa Família e os municípios do Estado de Minas Gerais.

Os dados foram operacionalizados utilizando-se o programa "Statistic Package for Social Science ${ }^{\mathrm{TM}}$ " e, posteriormente, analisados de forma quantitativa e qualitativa.

\section{Índice de Gestão Descentralizada (IGD)}

O IGD tem como propósito mensurar a eficiência e qualidade da gestão do Programa Bolsa Família. É um índice sintético, criado por meio da Portaria GM/MDS n ${ }^{\circ}$ 148, de 2006, e alterado pela Portaria MDS/GM n ${ }^{\circ}$ 754 de 20 de outubro de 2010, que tem como contrapartida governamental 
o apoio financeiro aos municípios do Programa Bolsa Família, em razão do desempenho na gestão do programa. O índice é calculado por meio de quatro fatores, conforme destacado na Equação 1 (MDS, 2011b).

$$
\mathrm{IGD}-\mathrm{M}=(\mathrm{F} 1 \times \mathrm{F} 2 \times \mathrm{F} 3 \times \mathrm{F} 4)
$$

em que:

IGD-M : Índice de Gestão Descentralizada Municipal

F1: Fator operação - é a média aritmética da qualidade e integridade das informações constantes no Cadastro Único (taxa de cobertura de cadastros); atualização da base de dados do Cadastro Único (taxa de atualização de cadastros); informações sobre o cumprimento das condicionalidades da área de educação (taxa de crianças com informações de frequência escolar); e informações sobre o cumprimento das condicionalidades da área de saúde (taxa de famílias com acompanhamento das condicionalidades de saúde);

F2: Fator de adesão Sistema Único de Assistência Social (Suas) - expressa se o município aderiu ao Suas, de acordo com a Norma Operacional Básica (NOB/Suas);

F3: Fator de informação da apresentação da comprovação de gastos dos recursos do IGD-M - indica se o gestor do Fundo Municipal de Assistência Social registrou no SUASWEB a comprovação de gastos apresentada ao Conselho Municipal de Assistência Social;

F4: Fator de informação da aprovação total da comprovação de gastos dos recursos do IGD-M pelo Conselho Municipal de Assistência Social (CMAS) - que indica se este colegiado registrou no SUASWEB a aprovação integral das contas apresentadas pelo gestor do Fundo Municipal de Assistência Social.

Para receber os recursos financeiros do IGD, o município deve cumprir quatro condições: atingir o valor mínimo de 0,55 no cálculo do Fator de Operação, e ainda o valor mínimo de 0,2 em cada uma das quatro taxas 
que o compõem; ter aderido ao Sistema Único de Assistência Social (Suas) (Fator de Adesão = 1); estar em dia com a apresentação da comprovação de gastos (Fator de Apresentação =1); e estar em dia com a aprovação total da comprovação de gastos (Fator de aprovação $=1$ ).

Os recursos transferidos no mês para apoio à gestão resultam da multiplicação do IGD-M pelo valor de referência de $\mathrm{R} \$ 2,50$ (dois reais e cinquenta centavos) e, desse produto, pelo número de famílias beneficiárias incluída na folha de pagamento do PBF do mês anterior ao do mês de referência do cálculo, até o limite da estimativa de famílias pobres no município, publicada pelo MDS. Soma-se a esse resultado o valor resultante da apuração de incentivos que podem ser $3 \%$ (três por cento) do valor apurado no item 1, proporcionais ao acompanhamento das famílias beneficiárias em situação de descumprimento de condicionalidades, que estejam em processo de acompanhamento familiar; $3 \%$ (três por cento) do valor apurado no item 1, quando o município atender, nos prazos estipulados, as demandas da Secretaria Nacional de Renda de Cidadania (Senarc) referentes à apuração de eventuais irregularidades na execução local do PBF; 2\% (dois por cento) do valor apurado no item 1, quando o município tiver $100 \%$ (cem por cento) dos dados referentes à Gestão Municipal atualizados há menos de um ano, registrados em sistema disponibilizado pelo MDS; e 2\% (dois por cento) do valor apurado no item 1 , quando o município apresentar ao menos 96\% (noventa e seis por cento) de cartões entregues na data de apuração do IGD-M.

Isso significa que os municípios com IGD-M igual a "1" recebem $\mathrm{R} \$ 2,50$ por família beneficiária a cada mês, mais incentivos. Além disso, fica assegurado aos municípios que atingirem os índices estabelecidos o repasse do valor mínimo de $R \$ 687,50$ (seiscentos e oitenta e sete reais e cinquenta centavos). Os valores transferidos serão calculados, portanto, de acordo com a Equação 2:

Valor a ser transferido $=\left(\right.$ IGD-M $\times \mathrm{R} \$ 2,50 \times \mathrm{n}^{\circ}$ de famílias 1$)+$ incentivos 
Ressalta-se que quanto maior o valor do IGD-M, maior será o valor do recurso transferido para o município. Por meio da construção do IGD-M, o MDS incentiva o aprimoramento da qualidade da gestão do Programa Bolsa Família em âmbito local, e contribui para que os municípios executem as ações que estão sob sua responsabilidade (MDS, 2011b).

De acordo com a Portaria MDS/GM n ${ }^{\circ} 754$, de 20 de outubro de 2010, os recursos transferidos devem ser utilizados nas seguintes atividades: gestão de condicionalidades; gestão de benefícios; acompanhamento das famílias beneficiárias; cadastramento de novas famílias, atualização e revisão dos dados contidos no Cadastro Único; atendimento às demandas relacionadas à fiscalização do Programa Bolsa Família; e introdução de programas complementares ao Programa Bolsa Família nas áreas de: a) alfabetização e educação de jovens e adultos; b) capacitação profissional; c) geração de trabalho e renda; d) acesso ao microcrédito produtivo orientado; e) desenvolvimento comunitário e territorial, dentre outras relacionadas às demandas de acompanhamento da gestão e fiscalização do PBF e do Cadastro Único, formuladas pelo MDS.

Não há menção nos informes e publicações do MDS e Programa Bolsa Família sobre sugestões de corte para a análise do IGD; apenas impõe-se que, para o recebimento do recurso financeiro, os municípios devem possuir um mínimo de 0,55 no índice. Dessa forma, propõe-se, neste estudo, elencar uma escala de qualidade com escores que permeiam de Péssimo a Excelente, sendo eles de 0,55 a 1 . Os resultados podem, todavia, assumir valores inferiores a 0,55 . Pelo fato de o de valor mínimo para receber os recursos ser este, adotou-se este valor como mínimo na escala, para avaliar a situação do município na gestão do Programa Bolsa Família (Figura 1).

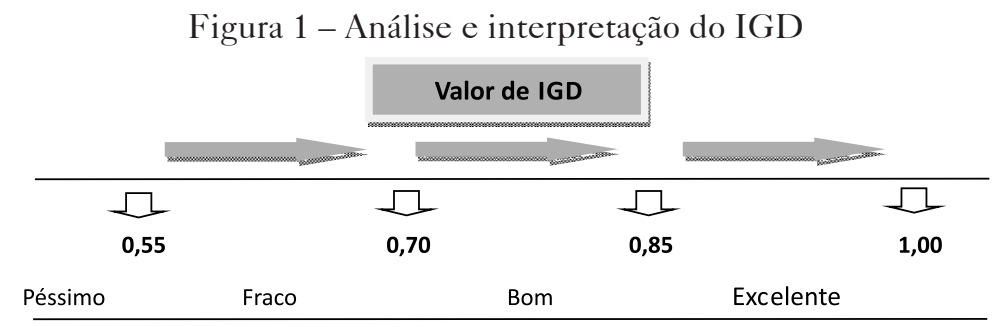

Fonte: Construção dos autores. 
Estudos anteriores como os de Monteiro (2008) e Silva (2009), apontam a existência de disparidades no Estado de Minas Gerais. Pretende-se, por meio deste estudo, explorar melhor essas diferenças, compreendendo o impacto da qualidade da gestão do Programa Bolsa Família no cumprimento das metas sociais de combate à miséria.

Logo, se faz necessário verificar sua eficiência, enquanto uma das proxies de qualidade da gestão pública do Programa Bolsa Família em Minas Gerais, bem como descrever sua contribuição para a melhoria da qualidade de vida e diminuição da desigualdade social na população-alvo.

\section{Resultados e Discussões}

\section{Análise das Variáveis Empregadas no Estudo}

Após Análise Exploratória dos Dados (AED), optou-se pela exclusão de alguns municípios com poder de distorção por possuírem um número muito elevado de habitantes, sendo eles Belo Horizonte (2.434.642), Contagem (617.749), Uberlândia (622.441), Juiz de Fora (520.612), Montes Claros (358.271), Betim (429.507), Ribeirão das Neves (340.033), Sete Lagoas (221.764), Governador Valadares (261.981), Uberaba (292.377), Ipatinga (241.720) e Santa Luzia (227.438). Estes municípios são considerados outliers (valores extremos), logo influenciariam nas medidas de tendência central, elevando demasiadamente a média da população mineira, não representando a realidade do Estado de Minas Gerais.

Observa-se, pela Tabela 1, que a média populacional dos municípios analisados em Minas Gerais, em 2010, foi de 15.793 habitantes. Deve-se destacar que embora tenha sido encontrado um alto desvio-padrão, a média apresenta conformidade com o Estado, onde cerca de 80\% dos municípios possuem população de até 20.000 habitantes e $92 \%$ até 100.000 habitantes (IBGE, 2011). Essa diferença de magnitude entre os municípios que com- 
põem a amostra, reflete a realidade nacional bem como a grande assimetria e disparidade observada entre os municípios mineiros, comum em um Estado com as dimensões de Minas Gerais.

Tabela 1 - Estatística descritiva das variáveis empregadas no estudo, Minas Gerais, 2010

\begin{tabular}{|c|c|c|c|c|c|c|}
\hline Variáveis & Mín. & Máx. & Média & $\begin{array}{l}\text { D e s v. - } \\
\text { Padrão }\end{array}$ & Assimetria & Curtose \\
\hline População & 889 & 213.277 & 15.793 & 22.360 & 3,673 & 17,124 \\
\hline $\begin{array}{l}\text { Recursos transferidos no } \\
\text { mês para apoio à gestão }\end{array}$ & 0,0 & $15.918,30$ & $2.320,37$ & $1.960,51$ & 2,521 & 8,514 \\
\hline $\begin{array}{l}\text { Teto de Recursos para } \\
\text { apoio à gestão }\end{array}$ & 345 & $31.812,50$ & $3.336,82$ & $3.158,855$ & 3,255 & 15,246 \\
\hline $\begin{array}{l}\text { Total de famílias benefi- } \\
\text { ciadas pelos programas }\end{array}$ & 37 & 9.967 & 1.089 & 1.153 & 2,756 & 10,558 \\
\hline
\end{tabular}

Fonte: Resultados da pesquisa.

O máximo de recursos transferidos no mês para apoio à gestão foi de $\mathrm{R} \$ 15.918,30$ e a média de $\mathrm{R} \$ 2.320,37$, por município, valor abaixo do teto, que teve como média $\mathrm{R} \$ 3.336,37$, o que demonstra a possibilidades de melhorias na gestão e no monitoramento das condicionalidades em âmbito municipal. Cabe ressaltar a presença de municípios com valores de recursos transferidos igual a zero (Ribeirão Vermelho, Riacho dos Machados, Pescador, Curral de Dentro, Leopoldina, Braúnas e Araújos), fato justificado por esses municípios não terem atingido o valor mínimo de 0,2 em uma das quatro taxas que compõem o fator operação. Ressalta-se que $80 \%$ do teto de recursos para apoio à gestão estão sendo repassados, considerando que a média do IGD no Estado foi de 0,80 (Tabela 2).

Além disso, como pode ser observado na Tabela 2, o município que apresentou o menor valor do IGD (mês) foi o de Leopoldina $(0,46)$, seguido por Ribeirão Vermelho $(0,51)$, o que indica mais uma vez a presença destes municípios entre os municípios que não receberam recursos para apoio à 
gestão, uma vez que o critério para obtenção de tal recurso é além de valor mínimo de 0,2 em uma das quatro taxas que compõem o fator operação, o alcance pelo menos de 0,55 no valor do IGD.

Embora uma evolução seja observada em relação ao aumento no valor obtido do IGD pelos municípios e a resultados encontrados em estudos anteriores, como o de Monteiro (2008), quando havia municípios que não recebiam recursos por não alcançar o valor mínimo estabelecido do IGD (mês), que naquela ocasião era de pelo menos 0,40 , ainda há a existência de municípios com escores insuficientes de IGD, uma vez que o valor mínimo passou a ser de 0,55. Como os recursos são limitados e as necessidades da população beneficiada crescentes, espera-se um esforço cada vez maior da gestão municipal na administração dos recursos, visando o bem-estar social.

Em pesquisa realizada pelo MDS/Senarc (2007), notou-se que para melhorar a estrutura de gestão do Programa Bolsa Família são utilizados recursos repassados para os municípios do IGD. Há investimentos na aquisição de computadores, material de consumo, melhoria do local de atendimento dos beneficiários, móveis, capacitação e contratação de recursos humanos.

Pode-se inferir, pelos resultados observados, que a melhora no IGD, em relação ao estudo anterior, em que a média era de 0,74 , passando agora para 0,80 , pode ter sofrido influência da realização desses investimentos, que podem ajudar na redução das dificuldades enfrentadas por vários municípios, que não possuem estrutura adequada para implementar as ações necessárias para a gestão descentralizada.

Deve-se destacar, conforme exposto por Souza (2007), a importância do processo de descentralização, uma vez que ele tem sido conhecido como uma das formas para melhorar a eficiência alocativa do setor público, pois aproxima a gestão pública dos cidadãos, concorrendo para o incremento da democracia, da cidadania, da responsabilidade social, do atendimento às 
necessidades da população, bem como contribui para introduzir concorrência na provisão de serviços públicos locais, com significativo impacto sobre a gestão pública.

Todas as variáveis, analisadas na Tabela 1, apresentaram assimetria positiva, o que demonstra valores concentrados na extremidade inferior da tabela de distribuição, além da influência de outliers positivos, assim como o coeficiente de curtose foi positivo, sendo, portanto, a distribuição em forma de cume, leptocúrtica, com uma concentração de dados em torno da média.

A Tabela 2 apresenta as variáveis empregadas na formação do IGD, juntamente com suas estatísticas descritivas. As variáveis "Índice de Validade de Cadastro" e "Índice de Atualização de Cadastro", apresentaram médias de 0,7602 e 0,7279 , respectivamente, sendo encontrada a presença de municípios com até 0,16 e 0,35. Os baixos índices verificados em alguns municípios podem ser indícios de problemas em relação à qualidade das informações no cadastro, principalmente no quesito Validade, que apresentou o menor valor. Cabe destacar que a imprecisão das informações pode gerar distorções à focalização e pagamento, dificultando ou até mesmo impossibilitando o acompanhamento das condicionalidades e tornando mais complexas as atividades de gestão de benefícios. Embora existam municípios com baixos índices, um ponto positivo é a presença de municípios com esses índices em boa situação, o que demonstra organização nos cadastros das famílias, podendo até ser apontados como modelo para os demais.

Tabela 2 - Estatística descritiva das variáveis empregadas na formação do Índice de Gestão Descentralizada, Minas Gerais, 2010

\begin{tabular}{lcccccc}
\hline Variáveis & Mín. & Máx. Média & $\begin{array}{l}\text { D e s v. } \\
\text { Pad. }\end{array}$ & $\begin{array}{l}\text { Assime- Curtose } \\
\text { tria }\end{array}$ & \\
\hline Índice de validade dos cadastros & 0,16 & 1,00 & 0,7602 & 0,1756 & $-0,386$ & $-0,549$ \\
$\begin{array}{l}\text { Índice de atualização de cadastro } \\
\text { Índice de condicionalidade edu- } \\
\text { cação }\end{array}$ & 0,35 & 1,00 & 0,7279 & 0,1202 & $-0,271$ & $-0,231$ \\
$\begin{array}{l}\text { Índice de condicionalidade saúde } \\
\text { IGD (mês) }\end{array}$ & 0,00 & 1,00 & 0,8992 & 0,0809 & $-4,074$ & 37,097 \\
& 0,46 & 0,97 & 0,8001 & 0,0759 & $-0,609$ & 0,478 \\
\hline
\end{tabular}

Fonte: Resultados da pesquisa. 
A “Condicionalidade Saúde” apresentou média 0,8078. O desviopadrão pode ser considerado baixo $(0,1699)$, ou seja, os dados encontramse concentrados em torno da média. Destaca-se que pode ser notada uma evolução em relação a estudo realizado por Monteiro (2008), no qual, esta variável apresentava uma média cerca de $60 \%$ menor, além de alto desviopadrão, resultante da relativa dispersão dos dados em torno da média.

A “Condicionalidade Educação" apresentou uma média de 0,8992, ainda maior que a da "Condicionalidade de Saúde", mostrando que tem havido preocupação quanto ao cumprimento dos objetivos do programa, garantindo a oferta deste serviço, demonstrando, ainda, a integração das ações do gestor do Programa Bolsa Família com as áreas da saúde e educação do município, auxiliando, reduzindo a vulnerabilidade social e melhorando a qualidade de vida da população atendida.

O cumprimento de tais condicionalidades é fundamental, uma vez que 50\% dos repasses do IGD são consequência do desempenho no acompanhamento das condicionalidades e um alto IGD - que significa mais recursos a serem utilizados na gestão do Programa Bolsa Família - é diretamente proporcional ao registro das informações de acompanhamento também na área de saúde (pré-natal, aleitamento materno, alimentação e vacinação) e educação (frequência escolar).

Um fato preocupante foi a presença de municípios com valores abaixo de 0,20 para as variáveis "Índice de Validade de Cadastro", "Índice de Atualização de Cadastro", "Condicionalidade Saúde" e "Condicionalidade Educação", fato que resulta em não repasse de recursos de apoio à gestão para o município. Observou-se que os municípios de Ribeirão Vermelho, Riacho dos Machados, Pescador e Curral de Dentro, obtiveram valores menores que 0,20 no índice de "Condicionalidade Saúde”. Leopoldina e Braúnas no índice de "Condicionalidade Educação", e o município de Araújos no índice de validade de cadastro, demonstrando a existência de municípios com uma gestão inadequada nesses quesitos, dificultando o acesso das famílias beneficiadas a seus direitos sociais básicos. Tais resultados demonstram 
que não tem ocorrido em todos os municípios uma administração pública voltada para o cidadão, no sentido colocado por Coutinho (2000), quando a administração pública direcionada ao cidadão pode ser definida como um modelo gerencial cujo objetivo é oferecer serviços públicos de qualidade, atendendo melhor às demandas dos seus usuários.

De acordo com o MDS (2011a), as condicionalidades têm como objetivo ampliar o acesso das famílias beneficiadas a seus direitos sociais básicos, principalmente os relativos à educação e saúde. É importante acompanhar o cumprimento das condicionalidades, posto que assim é possível identificar quais famílias estão com problemas de acesso, informando se elas utilizam ou não esses serviços, além de acompanhar aquelas famílias que não o fazem.

Pode-se observar que lacunas têm ocorrido, em Minas Gerais, tanto no acesso ao serviço quanto ao registro das informações. Assim, o desempenho da organização pública, em alguns municípios, não tem sido satisfatória, pois, conforme exposto por Souza (2006), o desempenho é aceitável ou satisfatório quando, por meio da utilização correta dos recursos, os objetivos estabelecidos no desenho da política pública são atingidos e as necessidades dos cidadãos são supridas.

Haja vista que o gestor local do Programa possui poder de decisão, de mobilização, de articulação e coordenação com outras áreas envolvidas na operacionalização do PBF (assistência social, educação e saúde), aponta-se que modificações devem ser realizadas na gestão, para que tais falhas possam ser sanadas e ocorra melhoria na execução do Programa.

Estudos, como o de Monteiro, Ferreira e Teixeira (2009), demonstram que a despesa com educação, voltada sobremaneira para o Ensino Fundamental, pré-escola, creche, alfabetização, de importância estratégica para os programas de transferência de renda condicionada a frequência escolar, aumentou no Brasil. Estes fatores tornam-se relevantes, pois o incentivo do Estado à participação escolar por meio dos programas sociais condicionadas 
à educação e o aumento dos gastos sociais nesta função, pode proporcionar também outros mecanismos de inclusão, como melhoria na infraestrutura das escolas e/ou qualidade do docente.

As variáveis expostas na Tabela 2, relacionadas ao IGD, apresentaram assimetrias negativas, ressaltando que, embora haja maior concentração das variáveis à direita, existe influência de outliers de menor valor. Os valores negativos encontrados para a curtose nas variáveis Índice de Validade dos Cadastros e Índice de Condicionalidade de Saúde, indicam uma distribuição mais plana, platicúrtica, ou seja, os valores estão relativamente dispersos em torno da média. As demais variáveis possuem distribuição em cume, leptocúrtica, com dados mais concentrados em torno da média.

\section{Análise do Desempenho Municipal Segundo o IGD}

Para melhor visualização do desempenho dos municípios quanto ao IGD, optou-se por adotar o critério usado por Monteiro (2008), com adaptações devido a mudanças no modelo de cálculo do IGD conforme especificado na Tabela 3 .

Foram observados 2 municípios com IGD abaixo de 0,55 , sendo classificados como de "Péssimo" desempenho no IGD, uma vez que não conseguiram atingir o índice mínimo para recebimento dos recursos, mostrando que estes municípios apresentam falhas na gestão do Programa Bolsa Família. Um fato positivo observado é que $90 \%$ dos municípios podem ser enquadrados, segundo a classificação estabelecida, como de "Bom" $(58,6 \%)$ ou "Excelente" (31,4\%) desempenho no IGD, ou seja, IGD acima de 0,74. Por outro lado, 9,8\% dos municípios apresentaram baixos escores para o IGD, ou seja, "Fraco" desempenho na gestão, mostrando mais uma vez a existência de falhas na gestão do Programa Bolsa Família nos municípios mineiros (Tabela 3). 
Tabela 3 - Frequência de municípios por escore de IGD, Minas Gerais, 2010

\begin{tabular}{llcc}
\hline Escores de IGD & $\begin{array}{l}\text { Classificação quanto ao desem- } \\
\text { penho no IGD }\end{array}$ & Frequência & Percentual (\%) \\
\hline Até 0,54 & Péssimo & 2 & 0,2 \\
0,55 a 0,69 & Fraco & 82 & 9,8 \\
0,70 a 0,84 & Bom & 493 & 58,6 \\
0,85 a 1,00 & Excelente & 264 & 31,4 \\
\hline
\end{tabular}

Fonte: Resultados da pesquisa.

Vale salientar, ainda, que uma análise da média de IGD por mesorregiões apresentou diferença significativa entre as regiões. Estudos como o de Soria Galvarro (2007), Souza (2007), Monteiro (2008) e Silva (2009), contextualizam as disparidades e necessidade de políticas públicas diferenciadas em Minas Gerais, pois este Estado é caracterizado por sérias desigualdades econômicas e sociais entre suas regiões e municípios, com áreas demarcadas por altas taxas de analfabetismo, concentração econômica da renda e da pobreza e baixo desempenho tributário local.

Quando realizada, graficamente, uma análise por mesorregiões (Figura 2) observou-se a coexistência, em uma mesma região, de municípios com desempenho excelente, e municípios com fraco e até mesmo péssimo desempenho. A existência dessas disparidades é fator agravante na elaboração de programas sociais, pois não se podem considerar municípios com condições iguais nem mesmo dentro de uma mesma região.

Neste contexto, analisar características dos municípios revela-se uma etapa fundamental para aportar conhecimentos que possam ser úteis ao planejamento de ações que visem a minimizar essas disparidades, ao passo que podem expor os municípios cujas práticas de gestão sirvam de referência para os demais. 
Figura 2 - Classificação dos escores de desempenho do IGD, Minas Gerais, 2010

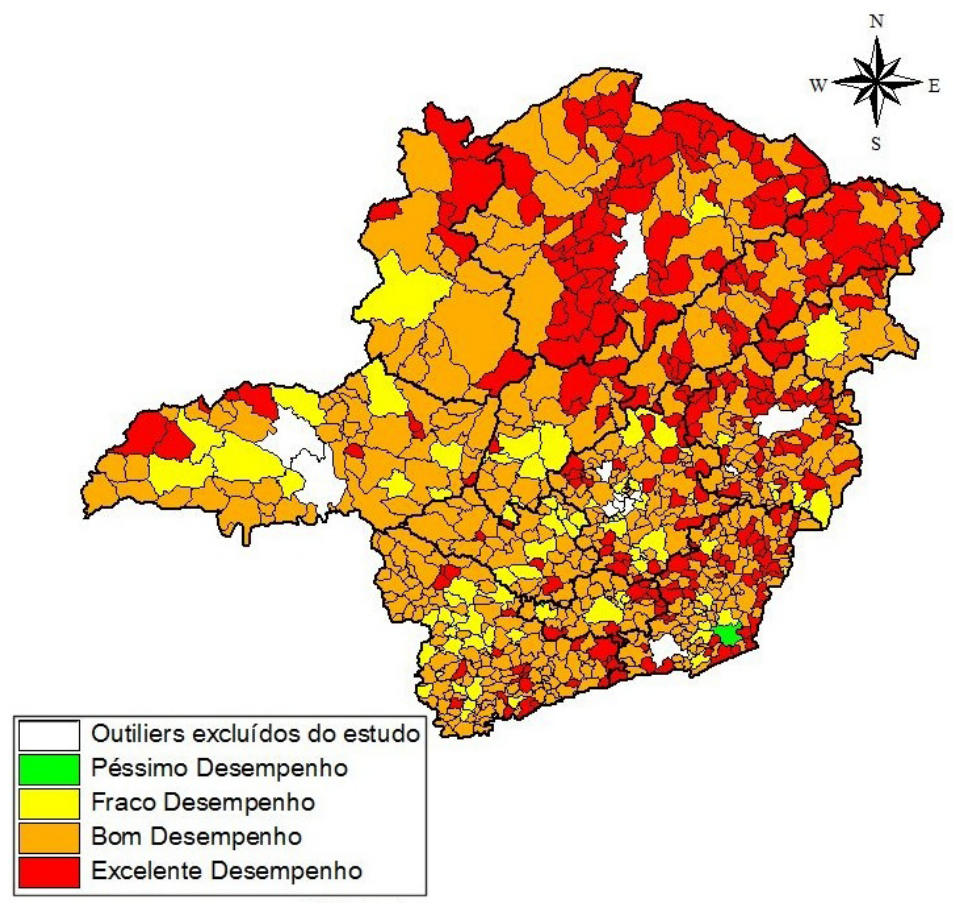

Fonte: Elaborada pelos autores.

No bojo desta discussão um fator intrigante é o fato de muitos municípios considerados em situação de menor bem-estar social, ou seja, possuidores de baixos indicadores sociais no Estado, como a região do Vale do Jequitinhonha e Norte de Minas, possuírem municípios com excelente desempenho na gestão do PBF. Este fator pode ser determinado pela melhor gestão do Programa e utilização dos recursos públicos, em virtude de gestores locais possuírem expertise na gestão de políticas sociais, em razão da realidade de vulnerabilidade existente, e/ou por experienciarem situações de escassez de recursos para operar o Programa, demandando ações mais focadas e efetivas no intuito de melhorar a execução do Programa. 


\section{Associação Entre as Variáveis do Estudo}

Pode-se observar a existência de associação linear entre o IGD e a população, recursos transferidos no mês para apoio a gestão, total de famílias beneficiadas e teto de recursos para apoio à gestão, conforme apresentado na Tabela 4. Os coeficientes negativos de correlação entre o IGD e as variáveis indicam uma relação linear inversa, ou seja, um aumento no IGD está associado a uma queda nos valores das demais variáveis, embora não se possam estabelecer relações de causalidade.

\section{Tabela 4 - Associação entre IGD e variáveis utilizadas no estudo em Minas Gerais, 2010}

\begin{tabular}{lcc}
\hline Variável & Coef. Correlação & Significância \\
\hline População & $-0,406$ & $0,000^{*}$ \\
Recursos Transferidos no Mês para apoio à gestão & $-0,077$ & $0,000^{*}$ \\
Teto de Recursos para apoio à gestão & $-0,331$ & $0,000^{*}$ \\
Total de famílias beneficiadas pelos programas & $-0,199$ & $0,000^{*}$ \\
\hline
\end{tabular}

* Significativo a $1 \%$.

Fonte: Resultados da pesquisa.

Logo, quanto maior a população do município, menor o valor do IGD, demonstrando fragilidades dos municípios mais populosos em gerir o Programa Bolsa Família, talvez pelas dificuldades na focalização da política pública e o acompanhamento de um grande número de famílias. Tal fato levanta questões acerca da dificuldade de municípios maiores em gerir programas de transferência de renda e combate à pobreza, podendo corroborar, ainda, com a postura de autores como Abrucio e Soares (2001) e Arretche (1996), que afirmam que, de um ponto de vista mais crítico, a descentralização pode transferir encargos sem que os municípios estejam preparados para produzir as políticas públicas, haja vista que uma política com a complexidade do PBF, que interage várias dimensões sociais e áreas da gestão pública, demanda qualidade e efetividade na composição de sua proposta. 
O mesmo acontece com o total de famílias beneficiadas por programas, os recursos transferidos no mês para apoio à gestão e o teto de apoio à gestão dos recursos, o que permite inferir que o aumento de famílias beneficiadas, dos recursos transferidos e o consequente aumento do teto de recursos, apresentam relação inversa com a eficiência da gestão do Programa Bolsa Família. Tal fato não pode ser apresentado como novo, pois, como exposto por Silva e Melo (2000), quanto mais complexa uma organização, mais difícil atingir a coordenação e o controle da gestão, principalmente pelo fato de que as políticas públicas são instituídas, fundamentalmente, por meio de redes de agentes públicos e de um campo interorganizacional.

Com o aumento do número de beneficiários, vem o consequente aumento das responsabilidades para a administração pública, principalmente municipal, por se tratar de um programa descentralizado, além da dificuldade de coordenação e a articulação ou mesmo integração entre as secretarias de assistência social, educação e saúde, no acompanhamento dos beneficiários do Programa e verificação das condicionalidades, resultando em fragilização da gestão e da operacionalização do programa.

\section{Considerações Finais}

Sabe-se que a ação pública no combate às mazelas sociais e na alocação eficiente dos recursos públicos, precisa ser mais efetiva. A incorporação das práticas de avaliação e monitoramento caminha nesse sentido, pois permite à gestão pública federal inovar no processo de tomadas de decisão e agregar melhorias às práticas administrativas.

Assim, o presente estudo objetivou verificar o desempenho da gestão pública do Programa Bolsa Família, bem como identificar fatores associados à eficiência e à qualidade da gestão do PBF em Minas Gerais. 
Quando analisado o desempenho dos municípios, segundo o critério estabelecido no IGD, observou-se um conjunto de municípios com escores de "Bom" a "Excelente" desempenho, porém cabe destacar a existência de municípios com "Péssimo" desempenho no IGD, uma vez que não conseguiram atingir o índice mínimo para recebimento dos recursos, mostrando que estes municípios apresentam falhas na gestão do Programa Bolsa Família. Tais observações demonstram a coexistência, em uma mesma mesorregião, de municípios com desempenho excelente e outros com fraco e até mesmo péssimo desempenho; fato este que sumariza a elevada discrepância intrarregional.

Um fato aparentemente contraditório, mas que tem se confirmado em estudos recentes, e encontra confirmação neste estudo e merece destaque, é o bom desempenho, entre as regiões estudadas, da mesorregião de Jequitinhonha, uma mesorregião que apresenta indicadores socioeconômicos deficitário mas que, quando o assunto é gestão de políticas sociais, tem obtido resultados satisfatórios.

Além dos fatores empregados na formação do Índice de Gestão Descentralizada, o tamanho dos municípios e a quantidade de beneficiários parecem influenciar a qualidade e eficiência da gestão do PBF. Ainda existem, entretanto, lacunas conceituais a serem investigadas, principalmente no sentido de explicar a relação entre o tamanho do município e a menor eficiência da gestão, observadas na região de estudo. Acredita-se, portanto, que além dos componentes empregados para a formação do IGD, variáveis como número de beneficiários e população merecem destaque na elaboração e reformulação de políticas públicas de proteção social.

Torna-se importante também a integração das ações do gestor do Programa Bolsa Família com as áreas de saúde e de educação no município, garantindo o cumprimento dos objetivos do programa e indo ao encontro da sua efetividade social, uma vez que o sucesso dos programas de transferência de renda está diretamente relacionado ao cumprimento das condicionalidades. 
Embora a maioria dos municípios apresente bons índices nas condicionalidades, o estudo demonstrou a existência de fragilidades tanto no atendimento das condicionalidades quanto no fornecimento correto das informações, o que torna mais complexas as atividades de gestão dos benefícios. O estudo revelou ainda que, embora a descentralização do sistema de gestão dos benefícios traga maior autonomia aos municípios, traz também maior responsabilidade para os gestores municipais, sendo de conhecimento comum as limitações operacionais de diversos municípios, em especial dos menores, isto porque, no caso do PBF, cabe ao gestor local toda a operacionalização, ou seja, gestão, monitoramento e fiscalização do Programa, e talvez haja municípios que não possuam expertise para tais responsabilidades.

Fica evidente a necessidade de aprimoramento dos mecanismos de monitoramento de informações e de acompanhamento das condicionalidades, visando a garantir à população beneficiada o acesso a direitos básicos como educação e saúde, atingindo assim o objetivo do Programa Bolsa Família, que é de reduzir a pobreza entre gerações e apoiar as famílias no cumprimento de seus direitos fundamentais.

\section{Referências}

ABRUCIO, F. L.; SOARES, M. M. Redes federativas no Brasil: cooperação intermunicipal no grande ABC. São Paulo: Cedec; Fundação Konrad Adenauer; Oficina Municipal, 2001.

ARNS, C. Posicionamento estratégico do Estado na política de assistência social. Florianópolis. Dissertação (Mestrado em Engenharia de Produção) - Universidade Federal de Santa Catarina, Florianópolis, 2005.

ARRETCHE, M. Mitos da descentralização: mais democracia e eficiência nas políticas pública? Revista Brasileira de Ciências Sociais, São Paulo, v. 11, n. 31, p. 44-66, 1996. 
BOLSA FAMÍLIA INFORMA - n. 38. 2008a. Governo federal regulamenta apoio financeiro aos municípios para gestão do Bolsa Família. Disponível em: <http://www. mds.gov.br/bolsafamilia/menu_superior/informe-pbf/informe-pbf gestores/paginas/ informebolsafamilia_edicao38.htm>. Acesso em: 3 jan. 2008.

BOLSA FAMÍLIA INFORMA, n. 4. 2008b. O papel do gestor municipal do Bolsa Família. Disponível em: <http://www.mds.gov.br/bolsafamilia/menu_superior/ informe-pbf/informe-pbf-gestores/paginas/informebolsafamilia_edicao04.htm > Acesso em: 3 jan. 2008.

CAMPOS, A. M. Accountability: quando poderemos traduzi-la para o português. Revista de Administração Pública, Rio de Janeiro, v. 24, n. 2, p. 30-50, fev./abr. 1990.

CASTANHAR, J. C. O que é política pública. Texto base para aulas. 2006. Mestrado (Administração Pública) - Ebape; FGV, Rio de Janeiro, 2006. (mimeo).

CASTIONI, R. Avaliação de políticas públicas: modelos e usos de avaliação de impacto em programas de formação profissional. VI Encontro Nacional de Estudos do Trabalho. São Paulo, 1999.

CHIECHELSKI, P. C. S. Avaliação de programas sociais: abordagem quantitativa e suas limitações. Revista Virtual Textos छ Contextos, Porto Alegre, ano IV, n. 4, p. 1-12, dez. 2005.

COUTINHO, M. J. V. Administração pública voltada para o cidadão: quadro teóricoconceitual. Revista do Serviço Público, Brasília, ano 51, n. 3, p. 40-73, jul./set. 2000.

CUNHA, R. E.; PINTO, B. H. B. C. O Programa Bolsa Família como estratégia para redução da pobreza e os processos de cooperação e coordenação intergovernamental para sua implementação. Biblioteca virtual Bolsa Família. 2011. Disponível em: < http:// www.ipc-undp.org/publications/mds/19M.pdf>. Acesso em: 24 jun. 2011.

FARAH, M. F. S. Parcerias, novos arranjos institucionais e políticas públicas no nível local e governo. Revista de Administração Pública, Rio de Janeiro, v. 35, n. 1, p. 119-144, jan./fev. 2001.

GIAMBIAGI, F.; ALÉM, A. C. D. Finanças públicas: teoria e prática no Brasil. Rio de Janeiro: Campus, 2000.

IBGE. Instituto Brasileiro de Geografia e Estatística. 2011. Cidade@. Disponível em: <http://www.ibge.gov.br/cidadesat/default.php>. Acesso em: 10 maio 2011. 
MATIAS-PEREIRA, J. Administração pública comparada: uma avaliação das reformas administrativas do Brasil, EUA e União Européia. Revista de Administração Pública, Rio de Janeiro, v. 42, n. 1, fev. 2008.

MDS. Ministério do Desenvolvimento Social e Combate à Fome. Secretaria Nacional de Renda e Cidadania. Análise da pesquisa sobre gestão descentralizada Programa Bolsa Família. 2007. Disponível em: <http:/www.mds.gov.br/bolsafamilia/menu_superior/ manuais-e -publicacoes-1>. Acesso em: 27 dez. 2011.

MDS. Ministério do Desenvolvimento Social e Combate à Fome. Secretaria Nacional de Renda e Cidadania. Análise da pesquisa sobre gestão descentralizada Programa Bolsa Família. 2007. Disponível em: <http:/www.mds.gov.br/bolsafamilia/menu_superior/ manuais-e-publicacoes-1>. Acesso em: 27 dez. 2011.

MDS. Ministério do Desenvolvimento Social e Combate à Fome. MDS em Números. 2011a. Disponível em: <http://aplicacoes.mds.gov.br/sagi/ascom/index.php?cut=aH R0cDovL2FwbGljYWNvZXMubWRzLmdvdi5ici9zYWdpL2FzY29tL2dlcmFyL2 luZGV4LnBocA==\&def=v>. Acesso em: 13 maio 2011a.

MDS. Ministério do Desenvolvimento Social e Combate à Fome. Índice de Gestão Descentralizada. 2011b. Disponível em: <http://mds.gov.br/bolsafamilia/gestaodescentralizada/indice-de-gestao-descentralizada-igd>. Acesso em: 3 jun. 2011.

MONTEIRO, T. M. A avaliação dos impactos sociais dos programas de governo. In: VII Congreso Internacional del Clad sobre la Reforma del Estado y de la Administración Pública. Lisboa, Portugal. 8-11 oct. 2002.

MONTEIRO, D. A. A. M. Alocação de recursos e eficiência na gestão do Programa Bolsa Familia. 2008. Dissertação (Mestrado em Administração) - Universidade Federal de Viçosa, Viçosa, MG, 2008.

MONTEIRO, D. A. A.; FERREIRA, M. A. M.; TEIXEIRA, K. M. D. Determinantes da gestão do Programa Bolsa Família: análise do índice de gestão descentralizada em Minas Gerais. Saúde e Sociedade (USP. Impresso), São Paulo, v. 18, n. 2, p. 214-226, abr./jun. 2009.

MPOG. Ministério do Planejamento, Orçamento e Gestão. Gestão pública para um Brasil de todos: um plano de gestão para o governo Lula. Brasília: MP; Secretaria de Gestão; Seges, 2003.

ORTIZ, L. Descentralização e a municipalização da saúde. 2007. Disponível em: <http:// www.comciencia.br/reportagens/ppublicas/pp06.htm>. Acesso em: 20 dez. 2007. 
PRZEWORSKI, A. Sobre o desenho do Estado: uma perspectiva agente x principal. In: BRESSER-PEREIRA, Luiz Carlos; SPINK, P. (Orgs.). Reforma do Estado e administração pública gerencial. Rio de Janeiro: FGV, 1998.

SANTOS, S. M. C.; SANTOS, L. M. P. Avaliação de políticas públicas de segurança alimentar e combate à fome no período de 1995-2002. 1 - Abordagem metodológica. Caderno de Saúde Pública, Rio de Janeiro, v. 23, n. 5, p. 1.029-1.040, maio 2007.

SILVA, A. A. P. Eficiência na alocação de recursos públicos e qualidade de vida nos municípios mineiros. 2009. Dissertação (Mestrado em Administração) - Universidade Federal de Viçosa, Viçosa, MG, 2009.

SILVA, P. L. B.; MELO, M. A. B. O processo de implementação de Políticas Públicas no Brasil: características e determinantes da avaliação de programas e projetos. NEPP-Unicamp, Caderno n. 48, out. 2000.

SORIA GALVARRO, M. D. P. S. Q. Descentralização da saúde: análise das disparidades regionais em Minas Gerais. 2007. Dissertação (Mestrado em Administração) - Universidade Federal de Viçosa, Viçosa, MG, 2007.

SOUSA, R. P. Avaliação e gestão de políticas públicas: notícias de uma relação muito delicada. XI Congreso Internacional del Clad sobre la Reforma del Estado y de la Administración Pública. Ciudad de Guatemala, 7-10 nov. 2006.

SOUZA, C. Governos locais e gestão de políticas sociais universais. São Paulo em Perspectiva, São Paulo, v. 18, n. 2, p. 21-47, jun. 2004.

SOUZA, C. Políticas públicas: uma revisão de literatura. Sociologias, Porto Alegre, ano 8, n. 16, p. 20-45, jul./dez. 2006.

SOUZA, C. O. Esforço fiscal e alocação de recursos nos municípios da Zona da Mata de Minas Gerais. 2007. Dissertação (Mestrado em Administração) - Universidade Federal de Viçosa, Viçosa, MG, 2007.

TROSA, S. Gestão pública por resultados: quando o Estado se compromete. Brasília, DF: Enap, 2001. 